\title{
Seropositivity of Toxoplasmosis in Pregnant Women by ELISA at Minia University Hospital, Egypt
}

\author{
Amany M. Kamal', Azza K. Ahmed ${ }^{1, *}$, Manal Z. M. Abdellatif', Mohamed Tawfik², Ebtesam E. Hassan ${ }^{3}$ \\ ${ }^{1}$ Department of Parasitology, Faculty of Medicine, Minia University, Minia 61519, Egypt; ${ }^{2}$ Department of Obstetrics and Gynecology, Faculty of \\ Medicine, Minia University, Minia 61519, Egypt; ${ }^{3}$ Department of Public Health and Preventive Medicine, Faculty of Medicine, Minia University, \\ Minia 61519, Egypt
}

\begin{abstract}
Toxoplasmosis is considered as an important risk factor for bad obstetric history $(\mathrm{BOH})$ and one of the major causes of congenitally acquired infections. The present study aimed to estimate the seropositivity of $T$. gondii infection and associated risk factors among the attendees of high risk pregnancy and low risk antenatal care clinic of Minia Maternity and Pediatric University Hospital, Minia, Egypt. The study was carried out from April 2013 to April 2014 through 2 phases, the first phase was case-control study, and the second phase was follow-up with intervention. A total of 120 high risk pregnant and 120 normal pregnant females were submitted to clinical examinations, serological screening for antiToxoplasma IgM and IgG antibodies by ELISA, and an interview questionnaire. Seropositive cases were subjected to spiramycin course treatment. The results showed that the seroprevalence of toxoplasmosis in high-risk pregnancy group was $50.8 \%$, which was significantly different from that of normal pregnancy group $(P<0.05)$. Analysis of seropositive women in relation to $\mathrm{BOH}$ showed that abortion was the commonest form of the pregnancy wastage (56.5\%). The high prevalence of $T$. gondii seropositive cases was observed in the age group of 21-30 years. Post-delivery adverse outcome was observed in $80.3 \%$ of high-risk pregnancy group compared to $20 \%$ of normal pregnancy group. There was a statistically significant relationship between seropositivity and living in rural area, low socioeconomic level, and undercooked meat consumption $(P<0.05)$. Serological screening for anti-Toxoplasma antibodies should be routine tests especially among high-risk pregnant women.
\end{abstract}

Key words: Toxoplasma gondii, toxoplasmosis, high-risk pregnancy, neonatal outcome, seropositivity, ELISA

\section{INTRODUCTION}

Toxoplasma gondii is one of the opportunistic obligate intracellular parasites with cats as the definitive host, while humans and animals act as intermediate hosts [1]. Human infections occur by different ways such as ingestion or handling of raw or partly cooked meat containing tissue cysts, direct contact with cats, and/or from the consumption of water or food contaminated by oocysts discharged in the feces of infected cats [2].

Congenital toxoplasmosis occurs when mother is primarily infected with T. gondii during pregnancy, and the infection spreads to the developing fetus across the placenta with possible serious problems for the fetus, including chorioretinitis, intracranial calcifications, hydrocephalus, and even stillbirth

- Received 13 April 2015, revised 1 September 2015, accepted 3 September 2015.

*Corresponding author (saraa96@yahoo.com)

(c) 2015, Korean Society for Parasitology and Tropical Medicine

This is an Open Access article distributed under the terms of the Creative Commons Attribution Non-Commercial License (http://creativecommons.org/licenses/by-nc/3.0) which permits unrestricted non-commercial use, distribution, and reproduction in any

medium, provided the original work is properly cited.
[3]. The degree of severity of the disease depends on the gestational age as severe fetal affection occurred with early gestational age infection [4].

Toxoplasmosis is considered as an important risk factor for bad obstetric outcome $(\mathrm{BOH})$ and one of the major causes of congenitally acquired infections $[5,6]$. Therefore, early diagnosis of toxoplasmosis is a crucial step to start treatment on time to minimize the trans-placental transmission $[4,7]$. Toxoplasmosis is usually diagnosed by serological tests that measure Toxoplasma specific IgM and IgG antibodies [3]. The prevalence of chronic Toxoplasma infection by serological test was $64.7 \%$ in Egypt [8].

Thus, this study aimed to determine the extent of seropositivity of T. gondii infection among antenatal women with $\mathrm{BOH}$ and previous normal obstetric history attending antenatal care clinic of Minia Maternity and Pediatric University Hospital, Minia, Egypt. In addition to analyze the seropositivity in relation to the type of $\mathrm{BOH}$ and the age of the study subjects, the current study conducted to assess the outcome of current pregnancy among those with seropositivity. Also, the research 
aimed to correlate the seropositive patients to the demographic risk factors of $T$. gondii among the study groups.

\section{MATERIALS AND METHODS}

\section{Study design and setting}

This study was carried out between the period of April 2013 to April 2014 at the high risk pregnancy care clinic and the low risk antenatal care clinic of Minia Maternity and Pediatric University Hospital, Minia, Egypt.

Inclusion criteria of antenatal women of reproductive age with previous $\mathrm{BOH}$ (group I) was spontaneous abortion, missed abortion, intrauterine fetal death, still births, preterm deliveries, congenital malformations, perinatal death, unexplained early neonatal death, women having mentally retarded children in earlier pregnancies, and unexplained seizures. Exclusion criteria by clinical examination and laboratory investigations was other causes of fetal wastage, such as hypertension, diabetes mellitus, Rh incompatibility, physical causes of abortion, and consanguinity. Subjects with known causes of fetal wastage were excluded from the study. Normal pregnancy (group II) included multiparous age-matched antenatal women without $\mathrm{BOH}$ attending the same clinic.

All seropositive cases were treated with spiramycin in a dose of 3 million IU twice a day and for 2 weeks (according to the standard protocol of the Department of Obstetrics and Gynecology, Faculty of Medicine, Minia University). Then, they were followed to assess the outcome of their pregnancy.

To work out the required sample-size for the determination of seropositivity in antenatal women with $\mathrm{BOH}$, the equation suggested by Schiesselman [9] was used. Considering $46.2 \%$ seropositivity of toxoplasmosis in women with $\mathrm{BOH}$ [10] and $12.3 \%$ in women without $\mathrm{BOH}$ [4], the desired sample-size was 100 (50 cases and 50 controls). To increase the strength and consistency of the association the sample was increased, and the study was conducted among 120 cases and 120 controls.

\section{Data collection}

A structured questionnaire was used to investigate known toxoplasmosis risk factors (name, age, residential area, level of education, monthly income, contact with cats, precaution during cat feces handling, hand washing after handling raw meat, consumption of raw or undercooked meat, consumption of raw vegetables, and exposure to soil). The questionnaires were applied at face-to-face interviews by the researchers. The ques- tions were answered orally by the participants and recorded by the researchers. The participant's name was written on the questionnaire, so that the risk of interviewing the same patient was eliminated.

\section{Serology}

From each of the study participants, a written consent was obtained to collect $2 \mathrm{ml}$ of venous blood using sterile disposable syringes under aseptic precautions. The blood samples were then transported to the Laboratory of Parasitology Department, Faculty of Medicine, Minia University, Egypt. Serum was separated from whole blood by centrifugation at 3,000 rpm for $5 \mathrm{~min}$, labeled, and kept in sterile microtubes at $-20^{\circ} \mathrm{C}$ for further serological examinations. Each serum sample was tested for the presence of anti-Toxoplasma antibodies IgM and IgG using commercial ELISA kit (Cal Biotech Inc., Spring Valley, California, USA) following the manufacturer's instructions. All positive cases for anti-Toxoplasma antibodies were re-tested at 3 weeks interval. The results were read by optical density at $450 \mathrm{~nm}$ on an ELISA reader (SLT Lab Instruments, A-5082 Grödig/Salzburg, Austria, serial no. 216692). Cut-off points and antibody index calculations were done according to manufacturers' recommendations to categorize seropositive (antibody index $>1.1$ ), borderline positive (antibody index 0.91.1 ), and seronegative (antibody index $<0.9$ ).

\section{Ethical approval}

The study protocol was approved by the scientific ethical committee of the Department of Parasitology and the Department of Obstetrics and Gynecology, Faculty of Medicine, Minia University at their monthly meeting on January 2013. A written informed consent was obtained from each participant.

\section{Statistical analysis of data}

Statistical analysis was done with software Statistical Package for the Social Sciences (SPSS version 17). The chi-square and Z-test (test of proportion) which is a test used for testing the significant difference between only 2 proportions were used to test statistically significant differences. The odd ratio (OR) and its $95 \%$ confidence interval (CI) were used to estimate the strength of the association between the T. gondii infection and the associated risk factors. Statistical significance was defined as a $P$-value of $<0.05$. 


\section{RESULTS}

Seroprevalence of $T$. gondii infection in high-risk pregnancy group (group I) was 61/120 women (50.8\%) vs 10/120 women $(8.3 \%)$ in normal pregnancy group (group II). Seropositivity of both groups for T. gondii IgM and/or IgG antibodies was shown in Table $1(P<0.05)$. Among the seropositive antenatal women with $\mathrm{BOH}$, abortion was the most common form of pregnancy wastage (39 cases; 56.5\%) (Table 2). The high prevalence of T. gondii seropositive cases was observed in age group of 21-30 years (Table 3). All pregnant women in this study were followed-up until delivery. Post-delivery adverse outcomes were observed in 49 cases (80.3\%) and 2 cases (20\%) in $\mathrm{BOH}$ and normal pregnancy, respectively (Table 4). Assessment of associated demographic risk factors among the seropositive cases was performed (Table 5). There was a significant T. gondii seropositivity in pregnant women living in rural area, of low socioeconomic stander, and with primary educational level, had daily contact with soil and consumed undercooked meat.

\section{DISCUSSION}

The present study showed that the seroprevalence of $T$. gondii infection among the high risk pregnancy group was 50.8\% vs $8.3 \%$ among the normal pregnancy group. These results

Table 1. Seropositive rate of $T$. gondii lgM and lgG antibodies with ELISA in high risk pregnant group

\begin{tabular}{|c|c|c|c|c|c|}
\hline \multirow{2}{*}{ Pregnant women } & \multicolumn{4}{|c|}{ No. of positive T. gondii Abs } & \multirow{2}{*}{$P$-value } \\
\hline & lgM positive (\%) & lgG positive (\%) & Both positive (\%) & Total (\%) & \\
\hline Group I (120) & $22(18.3)^{c}$ & $46(38.3)^{d}$ & $7(5.83)$ & $61(50.83)$ & 0.001 \\
\hline Group $\|(120)^{b}$ & $2(1.66)$ & 8 (6.66) & $0(0)$ & 10 (8.3) & \\
\hline
\end{tabular}

aHigh risk pregnancy group.

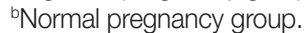

'lgM positive (lgM+ combined lgM and lgG).

lgG positive (lgG+ combined lgM and lgG).

Table 2. Previous obstetric histories in seropositive pregnancy

\begin{tabular}{lcc}
\hline Type of previous BOH & No. of subtotal & No. of positive T. gondii antibodies (\%) \\
\hline Early embryonic pregnancy loss ${ }^{\mathrm{a}}$ & 40 & $21(52.5)$ \\
Late abortion (12-24) weeks $^{\mathrm{a}}$ & 29 & $18(62.0)$ \\
Still birth (IUFD) delivery (24-40) & 24 & $11(45.8)$ \\
Preterm labor & 15 & $7(46.6)$ \\
Un-explained neonatal death & 8 & $3(37.5)$ \\
Congenital anomalies & 4 & $1(25.0)$ \\
Total cases & 120 & $61(50.83)$ \\
\hline
\end{tabular}

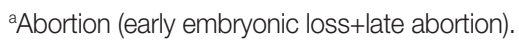

Table 3. Seropositive rate of $T$. gondii lgM and lgG antibodies in high risk pregnant group according to age

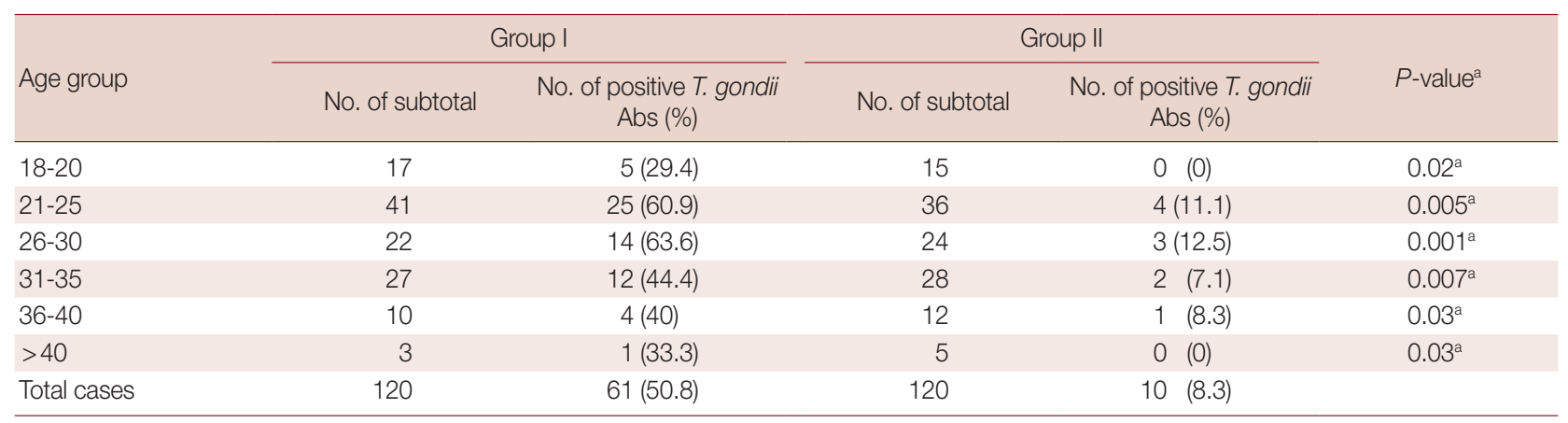

${ }^{a} P$-value was calculated by Z-test (test of proportion). 
Table 4. Clinical obstetric outcome(s) of seropositive pregnancy in $\mathrm{BOH}$ and normal pregnant groups

\begin{tabular}{|c|c|c|c|c|c|c|c|c|c|}
\hline \multirow{3}{*}{$\begin{array}{l}\text { Clinical obstetrics } \\
\text { outcome }\end{array}$} & \multicolumn{8}{|c|}{ No. of positive T. gondii Abs } & \multirow{3}{*}{$P$-value } \\
\hline & \multicolumn{4}{|c|}{ Group I } & \multicolumn{4}{|c|}{ Group II } & \\
\hline & No. of subtotal & $\lg M(\%)$ & $\lg G(\%)$ & Both (\%) & No. of subtotal & $\lg M(\%)$ & $\lg G(\%)$ & Both (\%) & \\
\hline Abortion & 18 & $8(44.4)$ & $6(33.3)$ & $4(22.2)$ & 1 & $1(100)$ & (0) & $0(0)$ & 0.09 \\
\hline Stillbirth (IUFD) & 16 & $3(18.8)$ & $12(75.0)$ & 1 (6.3) & 0 & $0 \quad(0)$ & $0 \quad(0)$ & $0(0)$ & $0.03^{\mathrm{a}}$ \\
\hline Preterm labor & 13 & $1(7.6)$ & $12(92.0)$ & $0 \quad(0.0)$ & 1 & (0) & $1(100)$ & $0(0)$ & 0.2 \\
\hline Congenital anomalies & 2 & $1(50.0)$ & $0 \quad(0.0)$ & $1(50.0)$ & 0 & $0 \quad(0)$ & $0 \quad(0)$ & $0(0)$ & 0.3 \\
\hline Normal baby & 12 & $2(16.6)$ & $9(75.0)$ & 1 (8.3) & 8 & 1 (12.5) & 7 (87.5) & $0(0)$ & $0.001^{a}$ \\
\hline Total & 61 & & & & 10 & & & & \\
\hline
\end{tabular}

$P$-value was calculated by comparison between IgM, IgG and both between Group I and Group II at each obstetric outcome.

${ }^{a} P$-value was calculated by the Fisher's exact test.

Table 5. The correlation of demographic risk factors and T. gondii seropositivity in pregnant women

\begin{tabular}{|c|c|c|c|c|}
\hline Demographic Characterization & No. of positive T. gondii Abs (\%) & No. of negative T. gondii Abs (\%) & OR $(95 \% \mathrm{Cl})$ & $P$-value \\
\hline $\begin{array}{l}\text { Residence: } \\
\text { Rural } \\
\text { Urban }\end{array}$ & $\begin{array}{ll}42 & (59.2) \\
29 & (40.8)\end{array}$ & $\begin{array}{ll}73 & (43.2) \\
96 & (56.8)\end{array}$ & $1.9(1.08-3.3)$ & 0.02 \\
\hline $\begin{array}{l}\text { Education level: } \\
\text { Illiterate } \\
\text { Primary } \\
\text { Secondary } \\
\text { University }\end{array}$ & $\begin{aligned} 2 & (2.8) \\
38 & (53) \\
19 & (26.8) \\
12 & (16.9)\end{aligned}$ & $\begin{array}{rr}7 & (4.1) \\
29 & (17.2) \\
75 & (44.4) \\
58 & (34.3)\end{array}$ & $0.68(0.48-0.97)$ & 0.03 \\
\hline $\begin{array}{l}\text { Occupation } \\
\text { House wives } \\
\text { Others }\end{array}$ & $\begin{array}{ll}44 & (62) \\
27 & (38)\end{array}$ & $\begin{array}{ll}87 & (51.5) \\
82 & (48.5)\end{array}$ & $1.5(0.87-2.7)$ & 0.1 \\
\hline $\begin{array}{l}\text { Socio-economic level } \\
\text { Low } \\
\text { Middle } \\
\text { High }\end{array}$ & $\begin{array}{rr}39 & (54.9) \\
29 & (40.8) \\
3 & (4.2)\end{array}$ & $\begin{aligned} 34 & (20.1) \\
102 & (60.4) \\
33 & (19.5)\end{aligned}$ & $4.8(2.6-8.8)$ & 0.001 \\
\hline $\begin{array}{l}\text { Contact with soil } \\
\text { Yes } \\
\text { No }\end{array}$ & $\begin{array}{ll}38 & (53.5) \\
33 & (46.5)\end{array}$ & $\begin{aligned} 64 & (37.9) \\
105 & (62.1)\end{aligned}$ & $1.8(1.1-3.3)$ & 0.02 \\
\hline $\begin{array}{l}\text { Contact with cats } \\
\text { Yes } \\
\text { No }\end{array}$ & $\begin{array}{ll}10 & (14.1) \\
61 & (85.9)\end{array}$ & $\begin{array}{rr}11 & (6.5) \\
158 & (93.5)\end{array}$ & $2.3(0.9-5.8)$ & 0.06 \\
\hline $\begin{array}{l}\text { Consumption of under-cooked } \\
\text { Yes } \\
\text { No }\end{array}$ & $\begin{array}{ll}49 & (69) \\
22 & (31)\end{array}$ & $\begin{aligned} 62 & (36.7) \\
107 & (63.3)\end{aligned}$ & $3.8(2.1-6.9)$ & 0.001 \\
\hline $\begin{array}{l}\text { Consumption of row vegetable } \\
\text { Yes } \\
\text { No }\end{array}$ & $\begin{array}{cc}71(100) \\
0 & (0)\end{array}$ & $\begin{array}{rr}169 & (100) \\
0 & (0)\end{array}$ & - & - \\
\hline Total & $71(100)$ & $169(100)$ & & \\
\hline
\end{tabular}

$P$-value $<0.05$.

$\mathrm{OR}$, odds ratio; $\mathrm{Cl}$, confidence interval.

were in concordance with other previous studies [4,5,11]. The high seroprevalence of toxoplasmosis among pregnant females with complicated obstetric history were observed than among normal pregnant females.

Among the high risk group, $12.5 \%$ were seropositive for IgM antibodies which indicates acute infection, 32.5\% were seropositive for only IgG antibodies which indicate chronic infection, and 5.8\% were seropositive for both IgM and IgG antibodies which indicates possible recent infection in the last 12 months. Our results were in concordance with other many similar studies $[4,6,11]$. In the normal pregnancy group, $6.7 \%$ were seropositive for IgG antibodies and 1.7\% were seropositive for IgM antibodies. These results agreed with El Deeb et al. [8] as they found IgG percentage higher than IgM among preg- 
nant women in Menofia governorate, Egypt.

Abortion was the most common form of pregnancy wastage $(56.5 \%)$ in our study and agreed with other reports $[4,11,12]$. Also, our result was similar to a previous study, a seroprevalence of $44.7 \%$ among aborted women from Qualyobia governorate, Egypt [13]. Although some reports $[4,14]$ stated that the seropositivity of $T$. gondii infection increases with age; however, our results showed that the seropositivity was observed more in the age group 21-30 years, which represent the child bearing age of women. The higher seroprevalence among pregnant women aged 20-30 years were also observed [15-17].

The relationship between maternal infection with T. gondii and the post-delivery adverse pregnancy outcomes was observed in 49 cases (80.3\%) and abortion was the highest risk among the adverse pregnancy outcomes. This was agreed with the meta-analysis study done by Li et al. [18]. The studies have proved that the presence of Toxoplasma cysts in chronically infected uteri lead to infection of the baby in the first trimester and often to recurrent miscarriages [19].

Treatment of a pregnant woman who acquired toxoplasmosis decreases the incidence of congenital infection by approximately $60 \%$ [7]. All seropositive cases were treated with spiramycin, and 20 cases (28.2\%) gave birth to normal babies. Although spiramycin reduces the risk of placental transmission, it is not always effective [20]. Additional PCR tests for amniotic fluid are recommended for the diagnosis of toxoplasmosis.

Our study showed that living in rural area, low socio-economic stander, primary educational level, and daily contact with soil were significant risk factors for $T$. gondii infection. Similar results were reported in other previous studies $[10,12,17]$. The life style of the residents in rural areas, the presence of domestic animals as well as the favorable environmental conditions for oocysts sporulation may contribute to this significance [21]. Also, women with higher socioeconomic standers and who were highly educated adopted appropriate hygienic measures regarding food and cooking habits which tend to eradicate the sources of disease transmission [22]. Consumption of undercooked meat was also a significant risk factor. This may be attributed to the habit of eating some Egyptian food containing undercooked meat as kabbab, shawarma, Hawawshy, and luncheon.

Negative association between Toxoplasma seropositivity and some documented potential risk factors among seropositive cases in this study may suggest a limited role of these factors in Minia City, Egypt. Climate and cultural differences as regards to sanitation and food habits may contribute to this variation.

\section{CONFLICT OF INTEREST}

We have no conflict of interest related to this work.

\section{REFERENCES}

1. Dubey JP. Toxoplasmosis of Animals and Humans. Beltsville, Maryland, USA. CRC Press. 2010.

2. Torgerson PR, Mastroiacovo P. Global burden of congenital toxoplasmosis: systematic review. Bull World Health Organ 2013; 91: 501-508.

3. Fricker-Hidalgo H, Cimon B, Chemla C, Darde ML, Delhaes L, L'ollivier C, Godineau N, Houze S, Paris L, Quinio D, RobertGangneux F, Villard O, Villena I, Candolfi E, Pelloux H. Toxoplasma seroconversion with negative or transient immunoglobulin $\mathrm{M}$ in pregnant women: myth or reality? A French multicenter retrospective study. J Clin Microbiol 2013; 51: 2103-2111.

4. Sarkar MD, Anuradha B, Sharma N, Roy RN. Seropositivity of toxoplasmosis in antenatal women with bad obstetric history in a tertiary-care hospital of Andhra Pradesh, India. J Health Popul Nutr 2012; 30: 87-92.

5. Kumari N, Morris N, Dutta R. Is screening of TORCH worthwhile in women with bad obstetric history: an observation from eastern Nepal. J Health Popul Nutr 2011; 29: 77-80.

6. Yasodhara P, Ramalakshmi BA, Lakshmi V, Krishna TP. Socioeconomic status and prevalence of toxoplasmosis during pregnancy. Indian J Med Microbiol 2004; 22: 241-243.

7. McLeod R, Remington IS. Toxoplasmosis (Toxoplasma gondii). In Behrman RE, Kliegman RM, Jenson HB, eds, Nelson Textbook of Pediatrics. 16th ed. Philadelphia, Pennsylvania, USA. WB Saunders. 2000, pp. 1054-1062.

8. El Deeb HK, Salah-Eldin H, Khodeer S, Allah, AA. Prevalence of Toxoplasma gondii infection in antenatal population in Menoufia governorate, Egypt. Acta Trop 2012; 124: 185-191.

9. Schiesselman JJ. Case-Control studies. Design, Conduct, Analysis. New York, USA. Oxford University Press. 1982, pp. 1-354.

10. Tammam AE, Haridy MA, Abdellah AH, Ahmed SR, Fayed HM, AL Sammani MA. Seroepidemiology of Toxoplasma gondii infection in women with first trimester spontaneous miscarriage in Qena governorate, Egypt. J Clin Diagn Res 2013; 7: 2870-2873.

11. Chintapally S, Padmaja, IJ. Seroprevalence of toxoplasmosis in antenatal women with bad obstetric history. Trop Parasitol 2013; 3: 62-66.

12. Senthamarai S, Sivasankari S, Apurba SS, Sandhya BK, Kumudavathi MS, Anitha C, Amshavathani SK. Seroprevalence of toxoplasmosis in pregnant women with bad obstetric history in a tertiary care hospital, Kanchipuram-a pilot study. Disease 2013; 3: $29-32$

13. Hussein AH, Ali AE, Saleh MH, Nagaty IM, Rezk AY. Seropreva- 
lence of Toxoplasma infection in Qualyobia governorate, Egypt. J Egypt Soc Parasitol 2001; 31: 355-363.

14. Zemene E, Yewhalaw D, Abera S, Belay T, Samuel A, Zeynudin A. Seroprevalence of Toxoplasma gondii and associated risk factors among pregnant women in Jimma town, south western Ethiopia. BMC Infect Dis 2012; 12: 337.

15. Spalding SM, Amendoeira MR, Klein CH, Ribeiro LC. Serological screening and toxoplasmosis exposure factors among pregnant women in south of Brazil. Rev Soc Bras Med Trop 2005; 38: 173-177.

16. Malarvizhi A, Viswanathan T, Lavanya V, Arul Sheeba Malar S, Moorthy K. Seroprevalence of Toxoplasma gondii in pregnant women. J Public Health Epidemiol 2012; 4: 170-177.

17. Siddiqui N, Shujatullah F, Khan HM, Rabbani T, Khan PA. Socioeconomic status and prevalence of toxoplasmosis in pregnant women with bad obstetric history. J Immunol Vaccine Technol 2014; 1: 101-103.

18. Li XL, Wei HX, Zhang H, Peng HJ, Lindsay DS. A meta-analysis on risks of adverse pregnancy outcomes in Toxoplasma gondii infection. PLoS One 2014; 9: e97775.

19. Ajayi GO, Omilabu SA. Prenatal diagnosis of cytomegalovirus (CMV), rubella, toxoplasmosis, varicella, parvovirus, herpes simplex and syphilis. The lagos programme experience. Clin Exp Obstet Gynecol 2010; 37: 37-38.

20. Cortina-Borja M, Tan HK, Wallon M, Paul M, Prusa A, Buffolano W, Malm G, Salt A, Freeman K, Petersen E, Gilbert RE, for the European Multicentre Study on Congenital Toxoplasmosis (EMSCOT). Prenatal treatment for serious neurological sequelae of congenital toxoplasmosis: an observational prospective cohort study. PLoS Med 2010; 7: e1000351.

21. Liu Q, Wei F, Gao S, Jiang L, Lian, H, Yuan B, Yuan Z, Xia Z, Liu B, $\mathrm{Xu}$ X, Zhu XQ. Toxoplasma gondii infection in pregnant women in China. Trans R Soc Trop Med Hyg 2009; 103: 162-166.

22. Mohammed TK. Seroprevalence of Toxoplasma gondii among pregnant women in Baghdad city. Iraq Acad Sci J 2011; 24: 2128. 